\title{
Brazilian Soap Opera and American TV Series: Narrativity According Barthes
}

\author{
Levi Henrique Merenciano ${ }^{1}$ \\ ${ }^{1}$ Universidade do Estado de Minas Gerais, Brazil \\ *Corresponding author: Levi Henrique Merenciano: levihm@gmail.com
}

\section{OPEN ACCESS}

Citation: Merenciano L.H. (2021) Brazilian Soap Opera and American TV Series: Narrativity According Barthes. Open Science Journal 6(1)

Received: $4^{\text {th }}$ November 2020

Accepted: $18^{\text {th }}$ January 2021

Published: $9^{\text {th }}$ February 2021

Copyright: (c) 2021 This is an open access article under the terms of the Creative Commons Attribution License, which permits unrestricted use, distribution, and reproduction in any medium, provided the original author and source are credited.

Funding: The author(s) received no specific funding for this work

Competing Interests: The author has declared that no competing interests exists.

\section{Abstract:}

This paper aims to compare two audiovisual tv products: a Brazilian soap opera "Avenida Brasil" (Brazil Avenue) and an American TV series Grey's Anatomy. The theoretical and methodological approach are structural narratology studies and French Semiotics, based on narratology studies influenced by Propp, Greimas and Barthes. The main goal is to analyze and compare the narrative structure of the first episodes of both TV productions by means the cardinal and catalyzer functions according to Roland Barthes narratives point of view. Conclusions show that American TV series in one hand produces narrativity more concerned with cardinal function, since it originates consecutive and especially consequent narrative actions. In the other hand Brazilian Soap Opera in general tend to produce catalysis functions, in which narrative structure does not necessarily create consequences for the narrative plot.

Keywords: Brazilian soap opera, American tv series, Structural narratology, Semiotics.

\section{Introduction}

It is intended to compare two audiovisual productions within the scope of its first two chapters: a Brazilian soap opera broadcast by Rede Globo de Televisão (Rede Globo TV), Avenida Brasil (Brazil Avenue), and the North American television series Grey's Anatomy, transmitted by ABC Domestic Television. The applied theoretical-methodological study involves structural narratology and French semiotics, which are based on narratological studies influenced by Propp, Greimas and Barthes. According to Barthes, the concepts of cardinal function and catalysis function are used to explaining narrative structures that differ in the case of the Brazilian soap opera compared to a North American TV series. 
By thinking part of the structure of these two audiovisual narratives, it is possible to establish which type of function is most recurrent in each one by analyzing and comparing narrative frames obtained from that tv products as they will be shown below ("Presentation of narrative spaces", "The characters and functions of Barthes"). In Brazilian teledramaturgy, based on the form of production influenced by Rede Globo TV, there are more recurrent functions of catalysis, by chaining the stories almost continuously and indefinitely. They are more related, therefore, to the syntagmatic characteristic of the narrative, giving fulfillment and filling the parts of the story, whether with dialogues, with the presentation of objects, places and people, often without meaning anything beyond of what it is shown. In other words, they produce narratives - according to Barthes' words - under the scope that "not even everything that is shown is functional", as the author says in Semiological Adventure (Barthes, 2001).

In Grey's Anatomy, on the other hand, there is a more economical model of narrative, whose attitudes, character descriptions and the way certain objects are manifested tend to mean more than the simple analog presentation of reality, and also to be recalled in other situations, giving scope for the construction of other narrative units. In this case, there is more narrative economy, which means that all lines said by the characters and all narrative situations are consequent and well used to produce other usable plots for the good of the narrative at all. In this regard, most of the elements that are originate in the narrative have a specific functionality, directed to another occasion in history. The initial line of the main character, Meredith Gray ("I am lost"), for example, was not a sentence in vain, as will be seen in the complete analysis, but a sign - a possibility of meaning - of another narrative unit of which it would be part, such as the challenge of making the medical diagnosis and proving that her own initial speech would be wrong. Or rather, from the good diagnosis made, Gray would be directed to the speech of his ability (and, therefore, of the resemblance to the talented mother) and not to her possible defeat as a doctor.

In short, it is interesting to note that in North American series, when a character appears as a possible opponent of the protagonist (or contrary to another important subject or action in the narrative), her or his action tends to generate future conflicts, leading the story to other important narrative units. In the case of the Brazilian soap opera from Rede Globo, it will be described in this paper that this narrative formula build itself differently, that is, in a simpler way, by chaining indeterminate more casual narrative actions.

\section{Formal description of folk tales}

All societies give meaning to life through narratological texts. However, the citizen, in his daily life, is not in the duty to create metalanguages that can explain the form and organization of the set of narratives that are part of his world. This task has been entrusted to literary studies, since in the sphere of Languages, narratology is still a question divided between literary studies and theories of linguistic inspiration in discourse. The focus here will be the linguistic study of narratives.

As the title of this article points out, it will be observed how two types of audiovisual narratives (a Brazilian soap opera and a North American TV series) conceive their narrativization, according to the examination model of structural narratologies. It will be investigate the narrative economy that comes from the 
North American model of television series production (the first episode of the Grey's Anatomy series) compared to the narrative form of the Globo TV Television soap operas (the first episode of the soap opera Avenida Brasil).

With regard to the structural examination of narratives, over the past hundred years there has been a concern with a more precise type of definition or one that meets a more linguistic criterion of description of the way in which they are organized. The analysis criteria sought, therefore, to correspond to a regular examination of their form. The concern of some authors dealing with the subject is divided between specialists in Theory of Literature, Structural Anthropology and Linguistics. The field of structural narratologies was a fertile ground for scholars, such as Propp, Jolles, Dundes, Todorov, Bremond, Barthes e Greimas.

Amongst the types of material, there are the narratives linked to the oral culture of different societies, exemplified through the material found in popular tales (myths, legends, fairy tales, etc.), collected within their communities. One of these attempts to compose the corpus of narratives and their formal study which offered a morphological description of the wonderful tales - is in the work of Vladimir Propp (2001), in his Morphology of the folktales ("Morfologia do conto maravilhoso").

When establishing a corpus of short stories of popular culture - with more than four hundred copies collected - the Russian scholar structurally describes the fantastic tales of this cultural universe to privilege the syntagmatic chain of 31 functions. They can be divided into spheres of action, such as that of the aggressor, the donor, the auxiliary, the hero, the false hero, etc., having, as a basic criterion, a fixed order of occurrence. In this description of Propp's contribution, a generalist concern with theory is observed, that is, in observing stable (invariant) elements and establishing, therefore, a common structure, characteristic of the tales of this cultural universe.

Also seeking to present a formal study of the popular tale, Jolles, a contemporary of Propp, classifies these popular narratives as simple forms. For the author, the evolution of these stories would pave the way, for example, to the forms of canonical literature (such as the novel), thus classifying it as one of the artistic forms derived from simple forms of narratives (Jolles, 1976, p. 192), in Simple Forms: Legend, Saga, Myth, Riddle, Saying, Case, Memorabile, Fairytale, Joke. It can be said that this thought is similar to that of the Bakhtin Circle, when it names the genres that are born from oral culture - the primary ones - so that they can constitute themselves in other cultural spheres as secondary genres, such as the literary forms of prose (romance, poetry) and imagistic and verbvisual syncretism (cinema, cartoons, comics, etc.).

\section{The influence of the Linguistics on narrative studies}

Complementing Propp's concept of function, Barthes (2001), in Semiological adventure (A aventura semiótica), thinks of the narratological description through the observation of narrative units, whose segments are presented as terms of a correlation: the functions. In turn, Alan Dundes (1996) observes in his "The Morphology of North American Indian Folktales" (A morfologia dos contos indígenas norte-americanos), through studies developed by Bremond (1973), in general, how the narrative units work. Dundes' description values the influence of Propp's formal model in order to show a rigorous structural scheme that presides over the narratives of the North American indigenous people. Barthes and 
Dundes are clear on one point: they seek a descriptive model for the narrative's minimal narrative units.

Initially, Barthes (2001) touches on the question of the capacity for syncretism between different languages (through the relationship of different semiotic systems), explaining that mankind seeks to shape its narratives through different substances of expression. The question can be summed up in the uniquely human fact of creating secondary semiotic systems - metalinguistic descriptions - from a natural language. Thus, Barthes agrees with the ability of the Linguistic discipline to describe, in a deductive way, a determined corpus of texts, assuming there is no way to account for all the narratives already produced. The closest to the ideal - that is, a serious and scientific study - would be in the analyst's effort to be successful in delimiting a corpus, provided it is produced within the scope of the linguistic reality (of natural language and world).

French Discursive semiotics also contributes to narratology studies. By making use of some concepts in the field of structural linguistics and semantics as well as the extension and application of notions by authors such as Propp, Jakobson, Hjelmslev, Saussure - French Semiotics approach contributed to the definition of the term "narrativity", from the Semiotics and Language: An Analytical Dictionary (Dicionário de Semiótica). In cooperating, thus, with the study of narratology, from Greimas and Courtés (1979, p. 295), the mentioned Dictionary broadly defines the term "narrativity": property that characterizes a certain type of discourse, establishing differences between narrative and nonnarrative discourses; way of organizing stories (tales, myths, legends) that unfold on the question of classes of discourse; principle of organization of any narrative discourse. According to this last definition, semiotics provides narratives with the status of "a whole of meaning". Thus, the different types of text, in their verbal or non-verbal manifestations, whether short stories, novels, comics, or even medicine inserts, have narrativity.

Thinking about the principles of discourse organization, as described by Greimas and Courtés (1979), Barthes questions whether, within the scope of the narrated, the whole of meaning has a determined functionality. The author's question, which follows below, summarizes the search for this article:

"In a narration, is everything functional? Does everything, down to the smallest detail, make sense? Can the narration be entirely cut into functional units? [...]. This is not a matter of art (on the part of the narrator), it is a matter of structure: in the order of speech, what is noticed is, by definition, remarkable: even when a detail seemed irreducibly insignificant [...]: everything has meaning or nothing has" (BARTHES, 2001, p. 114 - translated by us).

From this relevant questioning, it is necessary to point out whether everything would make sense in the narratives (the dialogue out of context, the presentation of an object, the description of an internal environment, the way the character looks at another or, in the cinema, how it breaks the fourth wall and stares at the viewer)? Barthes (2001) defines that the functional units can be divided into distributional and integrative, as it bases these notions on the work of Benveniste (1976), Problems in General Linguistics I (Problemas de Linguística Geral). The distributional ones explain the types of relationship between the same linguistic level, while the integrative ones deal relationships between different linguistic levels.

The distributional function corresponds to the syntagmatic sequences (such as the Propp functions). For example, in a novel, does the purchase of a revolver 
correlate with the moment when it will be used or prevented from being used, by the character who owns it or by someone else? In another hypothetical scene, when you go off-hook, is it implied that the character will hang up? Or will leaving it hanging generate other narrative sequences? These relations therefore have a logical and syntagmatic nature.

In turn, the integrative function concerns the indices, which are necessary for the sense of history. They can be understood by the characteristics of characters, in which the fact that James Bond, for example, is surrounded by administrative power (semiotically meaning by telephone devices) does not imply that he has means of communication available, but that he represents in totality of the discourse "being on the side of the order" (Barthes, 2001, p. 117-8).

Within these classes, two subclasses of narrative units can be determined: cardinal functions and catalysis functions. In a cardinal function, it is enough that the action to which they refer will open, maintain or close an alternative, in order for the story to continue, like a ringing telephone. The actions of answering or not answering the phone take the narrative to two or more alternatives of continuity (Barthes, 2001, p. 119). The catalysis functions, in turn, fill the narrative space between the cardinal functions, as a subsidiary notion that clusters around one nucleus or another, but that does not change the nature of the alternative. For example, the space that separates the act of James Bond answering a ringing phone. Such an action can be filled by a series of small incidents or descriptions that do not reflect the result or projections regarding the action of answering the phone, resulting in a purely chronological function. In the case of cardinal functions, the tie that joins them invests a functionality that, besides being chronological, is logical. For instance, while the catalysis functions are only consecutive units, the cardinal functions are consecutive and consequent (Barthes, 2001, p. 119), that is, they produce effect and, semiotically, they produce narrative transformation.

Thus, we will try to observe differences in the narrative organization of a Brazilian soap opera, compared to the way of narrating from a North American series, in order to report how each narrative makes use of cardinal and catalysis functions. Like said by Barthes:

"These functions may, at first sight, be insignificant; what constitutes them is not the spectacle [...] it is, if one can say so, the risk: the cardinal functions are the moment of risk of the narrative; among these alternative points [...] the catalysts have security zones" (BARTHES, 2001, p. 120 - translated by us).

It will be answered, therefore, if these ways of conceiving narrativity are to achieve a kind of narrative economy - privileging cardinal functions - or to zigzag in the style of a certain semiotic virtuosity - privileging just catalysis functions.

Analysis of a North American TV series and a Brazilian soap opera.

Gray's Anatomy is a TV series that is in its seventh season (in 2020) and started broadcasting in 2005. It shows the story of Gray, the daughter of one of the most famous surgeons in the country. Gray is on one of the country's most famous medical residency programs in Seattle. Together with her colleagues (Cristina, Izzy, George and Alex), she has to go through the challenge of working on medical shifts, learning to deal with the pressures of the profession and taking orders from Seattle Grace hospital attendants, in her first day of internship.

Globo's soap opera, Avenida Brasil, unlike the motto of the television series, shows Rita's revenge for being mistreated and deceived by her adoptive mother, Carminha. Little Rita's father, Genésio, is robbed and then run over by the 
vehicle of a famous football player, Tufão (equivalent a Typhoon), on Avenida Brasil Street, Rio de Janeiro. Carminha takes Genésio's inheritance and Tufão promises to take care of Carminha, by holding Genésio in his arms, before his death, in the middle of the street. In the following episodes, Rita is abandoned and raised by Lucinda. Since then, she meets his future love, Batata, his foster brother. Carminha marries Tufão, who adopts the boy Batata, while Rita is adopted by an Argentine couple, who baptize her as Nina. Being raised by Carminha and Tufão, the boy changes his name to Jorginho.

\section{Presentation of narrative spaces}

As for the presentations of these productions, Rede Globo's soap opera has a longer sequence of images with circular narrative elements (roughly, repetitive). In other words, it presents the place, focusing on "favelas". It shows the urban space of Rio de Janeiro, repeating the elements related to life on the "favela": relaxed people, beach, football and warmth. Therefore, it does not invest in the description - more seen in other audiovisual productions - of other touristic spaces relating these city (The Sugarloaf Mountain, Ipanema Beach, O Cristo Redentor).

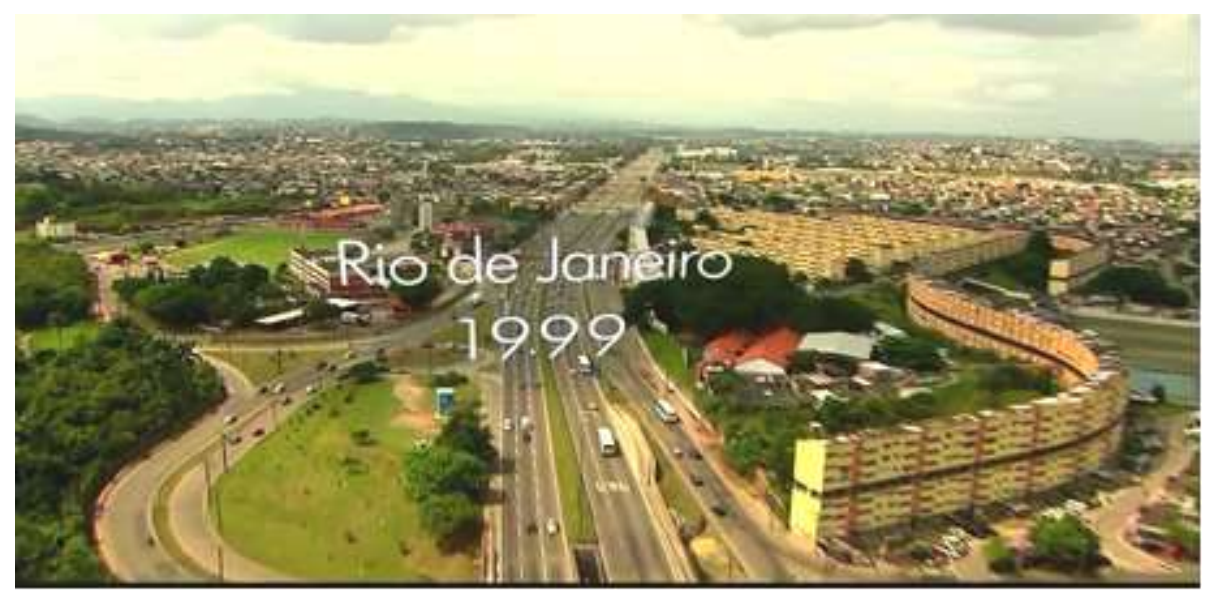

Figure 1: opening scene of Avenida Brasil (2012).

In the image below, a song plays, whose saying "beer" coincides with the act of you having a drink, while wearing your club's football shirt. This scene does not imply, therefore, a connection with other narrative units that will come, but it does make a spatial link to the musical content, uniting passion for football, heat and cold drink, a theme that will be realized in the course of the novel's speech with the theme "football, fame, money "and its realization through the making of football players from different divisions and their relationship with the people who live in the neighborhood of Divino. 


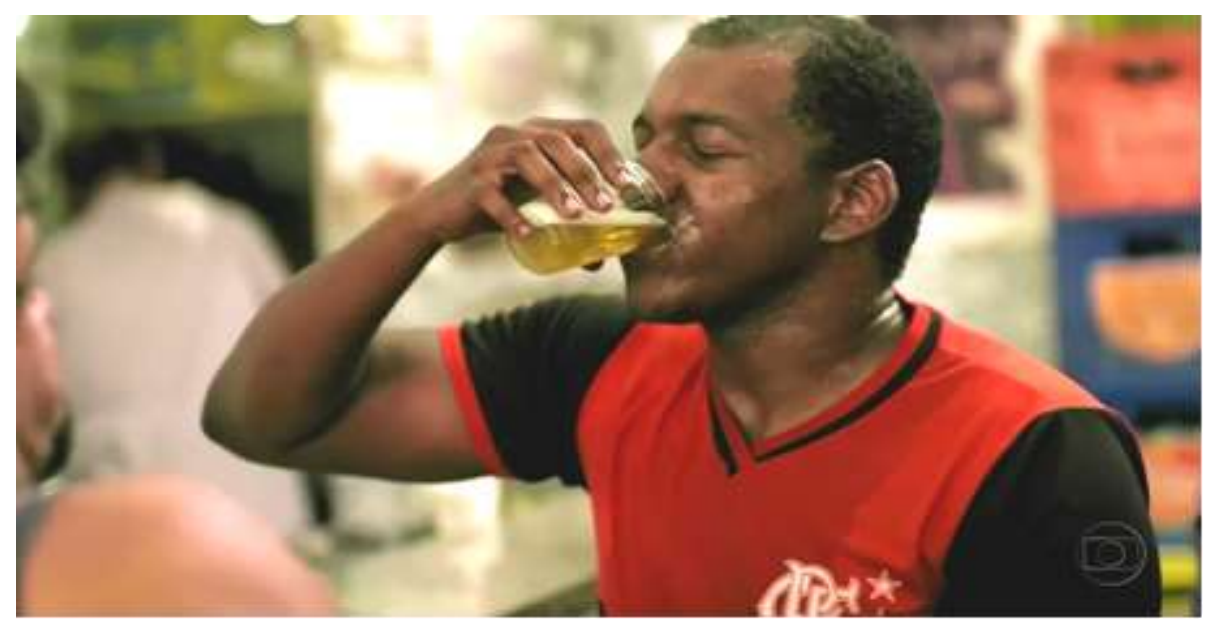

Figure 2: scene of everyday life in the narrative of the soap opera

The North American series Gray's Anatomy takes a different direction. In the first episode, there is a small performance of Seattle (the city where the hospital is located) after the scene of the main character, Meredith Gray, waking up with her lover. With a more objective type of narrative, the city is also shown, but focusing on Seattle's most striking space element, the Space Needle (Space Obelisk, in the background, closer to the "relationship" with the blue sky), taking as the element such architecture (city landmark) in almost all remaining chapters of the series.

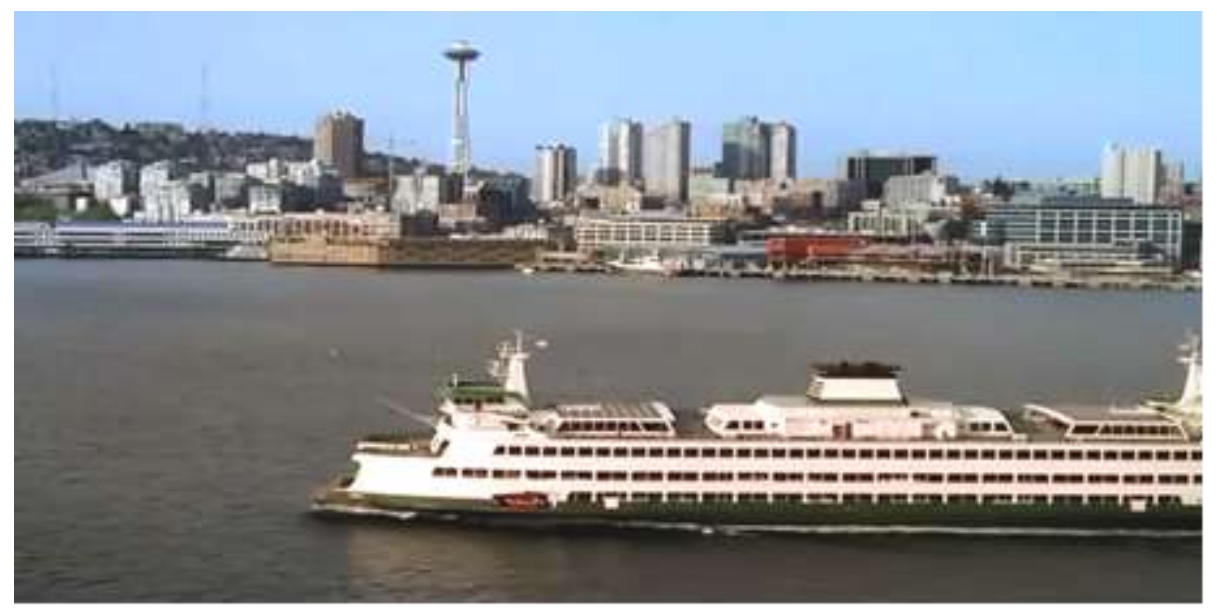

Figure 3: Gray's Anatomy opening scene, with Seattle obelisk in the background

At other times, there is also a reiteration of the North American flag in the background. In turn, the presentation of these narrative elements has no cardinal function, as they briefly describe the location and some representative elements of the narrated culture (the tower in a specific format, the quality of the hospital, the nation's flag in the background). 


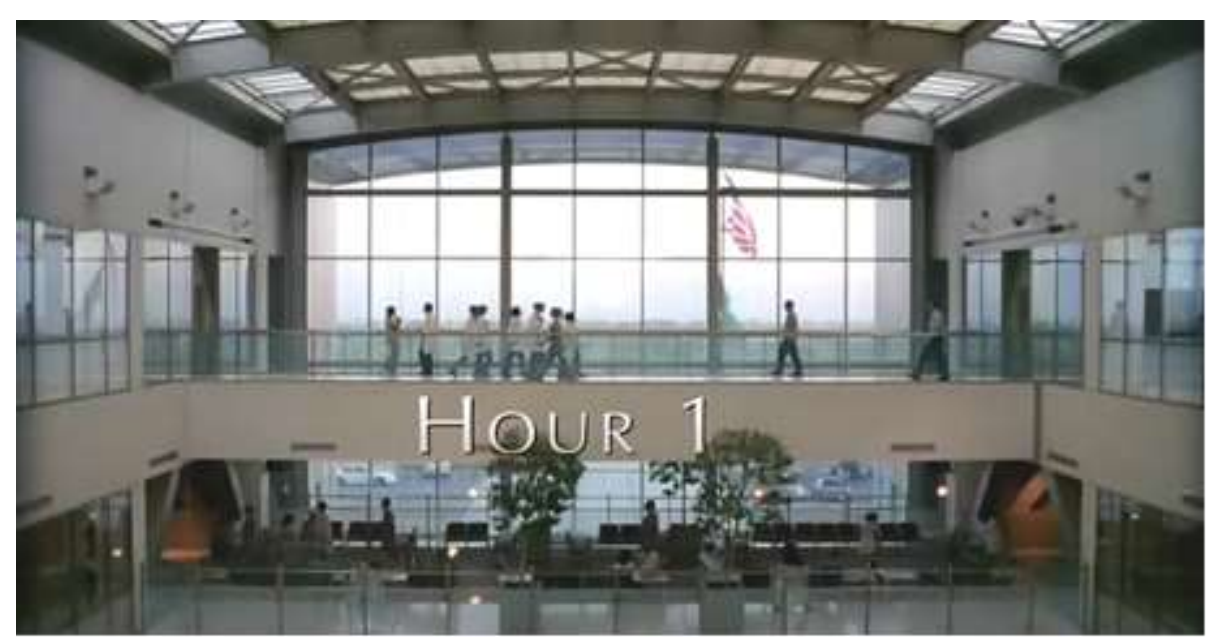

Figure 4: Seattle Grace hospital daily scene

\section{The characters and functions of Barthes}

Gray's Anatomy begins with a voice off (a process in which a narrator speaks, overlapping the ambient sound of the film), in which Meredith Gray, the protagonist, describes the importance of the game of life. She is in her apartment and sleeps with a stranger named Derek. She dismisses him and leaves quickly on the way to the Seattle Grace hospital to start her first day as an intern. There, he meets his colleagues, Cristina Yang, Isabel Stevens, George O'Malley and Alex Karev. Then she discovers that the boy she slept with is an attendant at the same hospital, where the love game begins, intermediated by games involving the hard profession of a doctor. During the brief start, the partially nude bodies of Gray and his lover are shown. She mentions the importance of the game and the fact that her mother was one of the most competent doctors of her generation (She says: "my mother was one of the best"), as seen in the smoky image of her thinking, when she dreams of her mother running surgery.

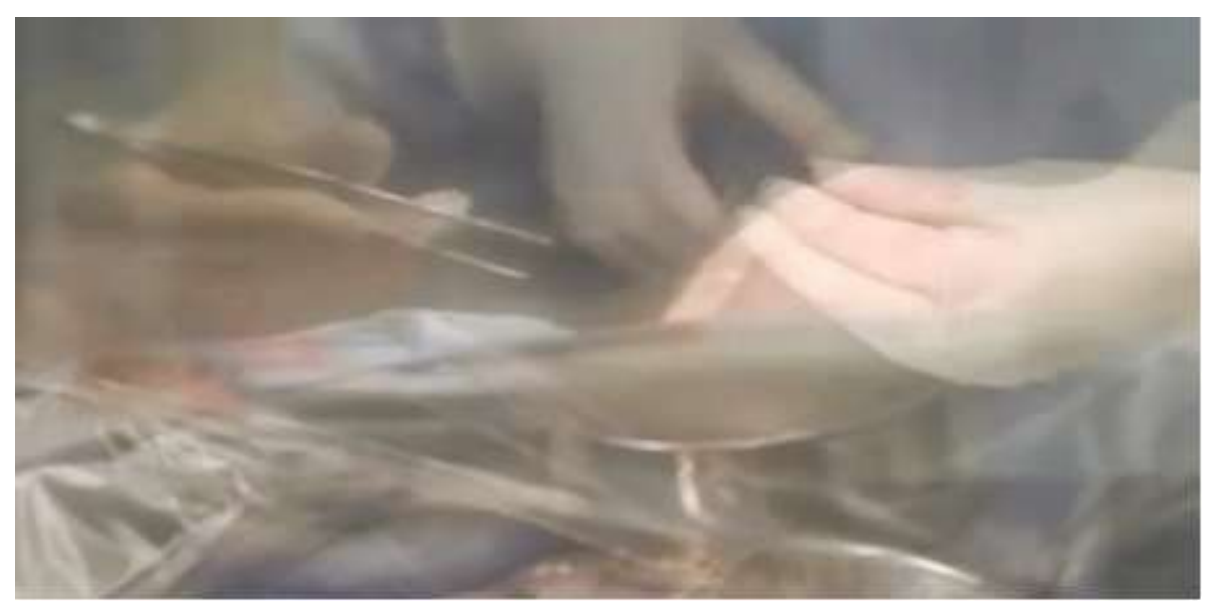

Figure 5: Grey's memory of his mother's vocation as a doctor 
After this scene of signs relating to medical competence, Gray claims to be, on the other hand, a little lost. The cut follows, and the next scene shows her in bed, with a sleepy face - making a counterpoint to the scene above - with a strange boy on her side in bed. This first scene already reveals a cardinal function. After the revelation of the game between professional and personal life, Gray finds herself in a situation where her statement opens up two narrative paths: she either stays in bed and affirms her doom (focus on the personal way) or gets up and goes to the first day of work as internal (focus on the professional way). In fact, such opposition seems to be constant in American series, in which characters are unable to cope with both paths at the same time, but, in general, they must always choose an alternative in order to renounce the other. It also refers to the old dilemma metaphorized by heart vs. brain. It is exactly the point where the narrative is economic, since it makes each line and actions of the protagonist count for the future of the narrative coherence and other actions will linked to that initial intentions and desires.

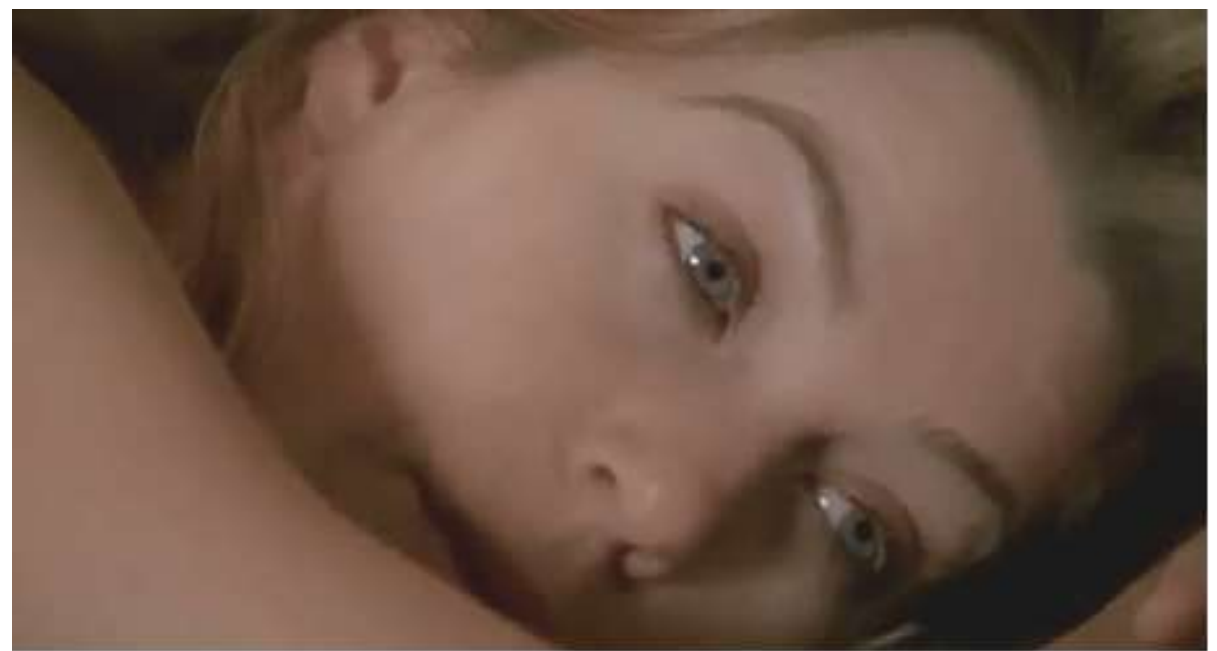

Figure 6: moment when Gray decides on personal and professional issues

This duel between the professional and the staff is maintained throughout the first episode. The coherence of her first line ("I am lost") follows during the episode. In another situation, Gray would need to call the responsible doctors if the patient is ill, however, it takes time to do so. For this reason, she receives harsh criticism from doctors, thus having her ability questioned. At the end of the shift period, Gray passes that first hard test and denies her initial journey of being lost. She manages to make a proper diagnosis of the patient's problem and saves her life. Your colleagues also have their skills questioned. George, for example, assures the patient's family that she will recover from the surgery, but the patient dies.

The predominant narrative functions in the Gray's Anatomy character description scenario are cardinal. Cristina Yang, for example, has Asian ancestry and an aggressive, logical, competitive behavior, relative to the masculine principle - her surname, Yang - from philosophy of Yin-Yang. All of his actions are built by means cardinal functions, as they are not only consecutive, but generate consequences, indicating her way of being less feminine and more aggressive, male.

All four characters presented are described in order to point out narrative units in which the details tend to have a functional nature, that is, each detail of the descriptions or the totality of the dialogues reflects on their way of being, by 
building other narrative units. O'Malley is the typical naive and kind countryman. Alex Karev is the impetuous and selfish descendant of Russians; Isabel (nickname Izzy) is the model who needs to prove that she is not only beautiful, but talented; and Meredith Gray is Jewish and the talented daughter of a famous doctor.

In the case of the soap opera Avenida Brasil, the functions are catalysis. There is a figurative and metaphorical name given to the character and football star, "Typhoon". It seems clear that his name depicts the typical speed and unpredictability of Brazilian soccer, but does not outline his personality. His figurative qualification of the name differs from his characteristics as a player. As a husband, he is naive, since he does not perceive his wife's malice and betrayal. Therefore, the name "Tufão" refers to narrative units made concrete by its past due to its soccer ability only. Its name is a descriptive data, since it does not reveal, at first a function that generates alternatives to the opening of other important narrative units. Only the narrative journey of the betrayed husband tends to perpetuate until the end (and actually matters if compared to the other characters) in the dramaturgy of this production.

It is interesting to point out that in North American series, when a candidate appears as a possible opponent of the protagonist (or contrary to another important character in the narrative), his action tends to generate future conflicts, leading the story to other important narrative units. In the case of the soap opera, this happens differently. It can be seen that at the beginning of the novel, when it presents Tufão fame through an open broadcast TV (which he watches in a bar), a man is observed, enjoying Tufão fame, but which is marked by the theme of the hypocrisy that surrounds celebrities and profiteers of occasion (image below).

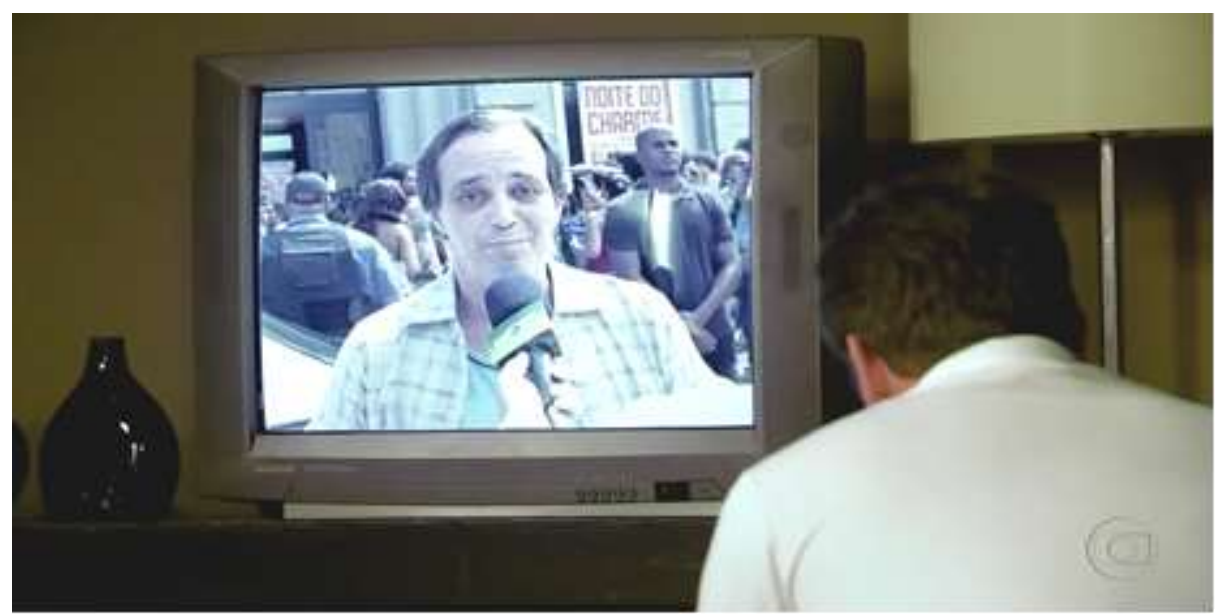

Figure 7: Typhoon, from the back, observes the levity of an old friend on TV.

The man interviewed says: "I was the one who gave the first ball as a gift to Tufão [...]". To which Tufão (on the right) responds indignantly: "This one is a liar ...". Then, he remembers when the guy didn't want to help him, what his father asks to reveal the issue. The narrative ends the subject, therefore, without the structure of this narrative giving any indication (opening the story) to a narrative unit that answered this question of having been ignored when he was not famous and now flattered on national television when is famous.

One can think how reasonable would be a response, in the course of the soap opera narrative, to this type of "fanfarrão" (ignorant) character, as the discourse of Avenida Brasil repeatedly elaborates the theme of fame, thus figuring, not only 
through the narrative path of Tufão, being relevant to the construction of the speech of this soap opera as a whole, but in the context of other soccer players, along with their "periguetes" (self-interested women). Thus, "responding" narratively to that flattering character would generate an enrichment of meaning for the soap opera, which would produce a form of narration organized through cardinal functions. This feature would offer more "risk to the narrative", as it does not have the "security zones provided by the analyzes", according Barthes.

\section{Conclusion}

By thinking part of the structure of these two audiovisual narratives (a Brazilian soap and a Tv series, which are similar by the chaining episodes), it is possible to establish which type of function is most persistent in each one.

In Brazilian teledramaturgy, based on the serial and the form of production influenced by the Rede Globo TV channel, there are, in a more frequent way, catalysis functions, which reinforce the ability to "enovelar" (narrate constantly), continuously chaining the stories. They are more related to the syntagmatic characteristic of the narrative, giving fulfillment and filling the parts of the story, whether with dialogues, with the presentation of objects, places and people, often without meaning anything beyond what is shown. In other words, they produce narratives - according to Barthes' words - under the scope that "not even everything is functional".

Concerning Grey's Anatomy, on the other hand, there is a more economical model of narrative, in which attitudes, character descriptions and the way certain objects are manifested tend to mean more than the simple analog imagistic presentation of reality, and also to be recalled in other situations, giving scope for the construction of other narrative units. On the other hand, Grey's anatomy builds more narrative economy.

In this regard, most of the elements that are originated in the narrative have a specific functionality, directed to another occasion in history. Grey's initial line, about being lost, was not a sentence in vain, but an premonition - a possibility of meaning - of another narrative units of which she would be part, such as the challenge of making the best diagnosis and proving that her own speech would be wrong. Or rather, from the good diagnosis made, Gray would be directed to the speech of her ability (and, therefore, of the resemblance to the talented mother) and not to his possible defeat as a doctor (at least in this first episode, because the end of each episode brings complications for the following ones).

\section{References:}

Avenida Brasil. (2012) Direção: José Luiz Villamarim e Amora Mautner. Produção: Rede Globo de Televisão. Basil. Rio de Janeiro, (Soap opera, daily).

Barthes, R. (2001). A Aventura Semiológica. São Paulo: Martins Fontes.

Benveniste, E. (1976) Problemas de Linguística Geral I. São Paulo: Edusp.

Bremond, C. Logique du Récit. Paris: Éditions Du Seuil.

Dundes, A. (1996) Morfologia e estrutura no conto folclórico. São Paulo: Perspectiva.

Greimas, A. J.; Courtés, J. (1979) Dicionário de Semiótica. São Paulo: Cultrix.

Grey's anatomy. (2005-2016) Production: Touchstone. United States. (TV series)

Jolles, A. (1976) Formas Simples. São Paulo: Cultrix.

Propp, V. (2001). Morfologia do Conto Maravilhoso. Copymarket, (Edição online). 